\title{
On the projection of future fire danger conditions with various instantaneous/mean-daily data sources
}

\author{
S. Herrera - J. Bedia - J.M. Gutiérrez • J. \\ Fernández • J.M. Moreno
}

Received: date / Accepted: date

\begin{abstract}
Fire danger indices are descriptors of fire potential in a large area, and combine a few variables that affect the initiation, spread and control of forest fires. The Canadian Fire Weather Index (FWI) is one of the most widely used fire danger indices in the world, and it is built upon instantaneous values of temperature, relative humidity and wind velocity at noon, together with 24 hourly accumulated precipitation. However, the scarcity of appropriate data has motivated the use of daily mean values as surrogates of the instantaneous ones in several studies that aimed to assess the impact of global warming on fire. In this paper we test the sensitivity of FWI values to both instantaneous and daily mean values, analyzing their effect on mean seasonal fire danger (seasonal severity rating, SSR) and extreme fire danger conditions $\left(90^{\text {th }}\right.$ percentile, FWI90, and FWI $>30$, FOT30), with a special focus on its influence in climate change impact studies. To this aim, we analyzed reanalysis and regional climate model (RCM) simulations, and compared the resulting instantaneous and daily mean versions both in the present climate and in a future scenario. In particular, we are interested in determining the effect of these datasets on the projected changes obtained for the mean and extreme seasonal fire danger conditions in future climate scenarios, as given by a RCM. Overall, our results warn against the use of daily mean data for the computation of present and future fire danger conditions. Daily mean data lead to systematic negative biases of fire danger calculations. Although the mean seasonal fire danger indices might be corrected to compensate for this bias, fire danger extremes (FWI90 and specially FOT30) cannot be reliably transformed to accommodate the
\end{abstract}

\section{S. Herrera}

Predictia Intelligent Data Solutions S.L. CDTUC Fase A, Planta 2-203. Avda. los Castros s/n 39005 Santander, Spain. E-mail: sixto@predictia.es

J. Bedia, J.M. Gutiérrez

Instituto de Física de Cantabria (IFCA-CSIC) - Universidad de Cantabria. 39005 Santander, Spain.

J. Fernández

Dpto. de Matemática Aplicada y CC de la computación- Universidad de Cantabria. 39005 Santander, Spain.

J.M. Moreno

Dpto. Ciencias Ambientales, Universidad de Castilla La Mancha. Av. Carlos III s/n, 45071 Toledo, Spain 
spatial pattern and magnitude of their respective instantaneous versions, leading to inconsistent results when projected into the future. As a result, we advocate caution when using daily mean data and strongly recommend the application of the standard definition for its calculation as closely as possible. Threshold-dependent indices derived from FWI are not reliably represented by the daily mean version and thus can neither be applied for the estimation of future fire danger season length and severity, nor for the estimation of future extreme events.

Keywords Climate Change $\cdot$ Fire Weather Index $\cdot$ Fire Regime $\cdot$ Regional Climate Models · Reanalysis Data I Iberian Peninsula

\section{Introduction}

Climate and weather are key controlling factors of wildfire occurrence and spread (Rothermel, 1972; Chandler et al, 1983), and studies around the globe show that fire activity is closely related to these variables (Flannigan and Harrington, 1988; Vázquez and Moreno, 1993; Littell et al, 2009; Carvalho et al, 2008; Good et al, 2008; Costa et al, 2011). Even at a global scale, a few climatic variables can reasonably explain fire activity (Krawchuk et al, 2009; Pechony and Shindell, 2010). Understanding the links between climate/weather and wildfires in the past is important for fire management planning in fire-prone regions. Furthermore, this understanding is utmost critical for projecting climate change impacts in future fire activity due to the projected changes in climate extremes favoring fire in many regions of the world (Seneviratne et al, 2012). Given an ignition source, different weather variables affect differently fire ignition probability and spread. Consequently, forest fires agencies have used for decades various fire danger indices to characterize fire potential in a region by combining the relevant climatic variables into one or a few values (Fugioka et al, 2009), leading to indices that act as meters that allow comparisons among fire seasons and across fire regions, and that can also be used to project future changes in fire potential due to global warming (Stocks et al, 1998; Brown et al, 2004; Hennessy et al, 2005; Moriondo et al, 2006).

The Canadian Fire Weather Index (FWI), based on the Canadian Forest Fire Danger Rating System (van Wagner, 1987), is one of the most widespread indices in the world. Besides Canada, other countries in North and South America, Europe and Asia are using it, and has even been proposed to be used as part of an early warning system for the whole world (de Groot et al, 2006). The FWI system is calculated using as input four variables (temperature, relative humidity, wind speed, and $24 \mathrm{~h}$ accumulated precipitation). These are used in a number of equations that end up producing several indices that aim to characterize fuel moisture content, fuel consumption, fire rate of spread and fire intensity (van Wagner, 1987). Identifying critical conditions is extremely important, taking into account that the relationships between index values and fire ignition and spread are non-linear (Wotton et al, 2009). Indeed, fires are extreme phenomena, and few fires account for a large percentage of the area burned (Strauss et al, 1989; Vázquez and Moreno, 1995). Hence, a correct calculation for current and future climate and in particular of extreme conditions is of paramount importance.

The original FWI was designed to use weather variables at noon (van Wagner, 1987). However, the required meteorological data are not always available, as it is the case for many countries, particularly when attempting to study current climate relationships with fire dating back long periods of time, and/or over extensive areas. 
The lack of appropriate data for FWI calculation has been a major limitation for many climate change studies using Global/Regional Climate Models (GCM/RCM respectively). For instance, in Europe some public climate databases providing regional climate scenarios, such as PRUDENCE (Christensen et al, 2007) or the most recent ENSEMBLES (van der Linden and Mitchell, 2009), store most RCM output variables as daily means.

As a result FWI is often computed using daily mean values, rather than noon values due to their better availability. Although some studies base the use of daily mean data on the good correlation with instantaneous values (e.g. Carvalho et al, 2010), a number of potential problems must be considered. For instance, FWI is commonly used to define fire danger categories (e.g., normally five: low, moderate, high, very high and extreme) using appropriate threshold values which vary depending on the geographical area (see, e.g. Wotton, 2009). Since daily mean values are usually lower than noon values, such calculations tend to underestimate critical events, important when we attempt to identify conditions leading to large fires or to project FWI under more extreme conditions in a future climate. Similarly, other threshold-dependent indicators derived from FWI, such as the number of days (or the frequency) above a certain threshold used to define the length of the fire season and frequency of certain high risk days (Moriondo et al, 2006; Giannakopoulos et al, 2009; Moreno et al, 2010) can be seriously affected. Whereas some studies take into account this issue and use the appropriate instantaneous model outputs (Stocks et al, 1998; Flannigan et al, 2005), others compute FWI using the daily means stored in these databases (e.g., Moriondo et al, 2006; Giannakopoulos et al, 2009; Carvalho et al, 2010). The effect of using daily mean inputs as opposed to noon values on extreme event detection and index magnitude has not been addressed yet by any study, thus impairing the interpretation and implications of a number of previous analyses using daily mean data.

The aim of this study is to analyze the effect that these two choices of temporal aggregation (instantaneous vs. daily means, i.e., 12-UTC FWI and daily mean FWI hereafter) have on index magnitude, frequency distribution and detection skill of extreme fire danger events. To this aim, we have focused on the particular case of fire danger projections of one RCM and on the ERA-Interim reanalysis on the Iberian Peninsula and part of the North African coast, a region with a sufficiently wide range of climatic conditions in order to obtain representative results. We emphasize that the aim of this study is neither to provide fire danger scenarios for this region, nor providing a general rule for daily mean FWI correction, but to analyze the effect on FWI of the temporal aggregation of its input variables and to highlight the possible deleterious effect that this may have on climate impact studies. Building upon previous research, we used ERA-Interim reanalysis data as quasi-observations of fire danger over this region (Bedia et al, 2012). The RCM simulations were coupled to ERA-Interim reanalysis and to the SRES-A1B scenario of one GCM (Nakićenović, 2000), thus providing an additional insight into the question addressed in this paper using both quasi-observations and climate model simulations.

\section{Data}

We considered two different data sources in our analyses: (1) a reanalysis product as a reference gridded data set and (2) RCM data in order to provide high resolution variables and future projections. These data are available for different time periods 
and we used their common period 1990-1999 to conduct this study. We also restricted the study to the summer season (June, July, August; JJA).

\subsection{Reanalysis data}

ERA-Interim represents the third generation reanalysis of the European Center for Medium-Range Weather Forecasts (ECMWF) in collaboration with many institutions (Dee et al, 2011). The atmospheric model and assimilation system used improves upon its predecessor, ERA-40, by providing a higher resolution $\left(\sim 0.7^{\circ}\right)$ and eliminating or significantly reducing some of the main problems described with ERA-40 (e.g., Sterl, 2004; Brands et al, 2012). ERA-Interim is available globally with 6-hourly frequency for the period from 1979 to the present day. The results of a previous study on the Iberian Peninsula show that ERA-Interim is the most advisable reanalysis product for FWI calculation, attaining the best agreement with local observations and also the best performance in extreme event detection when compared against other reanalyses (Bedia et al, 2012). We computed FWI from ERA-Interim using both instantaneous values at 12:00 UTC and daily mean values (averages of the four 6-hourly outputs in a given day). Thus, the 12:00 UTC reanalysis output is the best possible approximation to the required instantaneous FWI inputs at noon (14:00 local time in summer). Regarding precipitation, it is important to note that this variable is a forecast product in all reanalysis data sets (i.e., it is forecast by simulating forward in time from the analysis). ERA-Interim provides forecast variables at 3-hourly intervals from the analysis time. In order to avoid the initial spin up of the forecast model, we computed the accumulated precipitation from 12:00 UTC of the previous day to 12:00 UTC of current day by considering the difference between the values accumulated on forecast times 36 and 12 , based on the analysis at 00:00 UTC of the previous day.

\subsection{Regional Climate Model (RCM) Data}

In the present study, we used simulations performed within the ESCENA project (Jiménez-Guerrero et al, 2012; Domínguez et al, 2012). This project contributes to the Spanish national scenarios programme Escenarios-PNACC 2012. In particular, we used the WRF model (Weather Research and Forecasting; Skamarock et al, 2008) nested into the ERA-Interim reanalysis (often termed as "perfect" lateral boundary conditions). The simulation covers the period 1989-2008 and the spatial domain is centered over the Iberian Peninsula with a horizontal resolution of 25 kilometers. The reanalysis-driven simulation of the RCM provides a physically consistent realization of the regional climate and provides 3-hourly instantaneous data and also daily mean values. We used this simulation to compare the sensitivity of FWI to daily mean/instantaneous inputs in a climate modeling framework. We also analysed a transient future projection obtained with the RCM driven by a single GCM (ECHAM5-MPI-OM, run 2; Roeckner, 2007) forced by the SRES-A1B emissions scenario (Nakićenović, 2000) for the period 2011-2050. 
3 Methodology

\subsection{Fire danger climatology}

The FWI system is very briefly described in the following. The interested reader is referred to the detailed formulation provided by van Wagner (1987) or the recent review by Wotton (2009). The FWI system is composed of six standard components. Three of them are known as "fuel moisture codes" and model daily changes in the moisture content of forest fuels with different drying rates depending on the nature of these materials: the fine fuel moisture code (FFMC), the duff moisture code (DMC), and the drought code (DC). One of the major strengths of the FWI system lies in these three moisture codes, which track moisture in three layers of the forest floor critical to fire ignition, spread and suppression (Wotton, 2009). The next two components are related to fuel consumption and fire spread: the build-up index (BUI) and the initial spread index (ISI). Finally, FWI is obtained as a combination of the previous parameters, representing the intensity of a spreading fire as energy output rate per unit length of fire front, which is used as a general, dimensionless, daily-based indicator of fire danger (for a practical application of these indices to a particular type of fuel within our domain of calculations see Palheiro et al, 2006). Daily FWI values can be converted to a daily severity rating (DSR; van Wagner, 1987) by applying a simple power transformation. This transformation allows the aggregation of FWI over longer periods and takes into account the non-linear increase of fire severity with higher index values.

We computed FWI for the ERA-Interim and RCM data sets for the 1990-1999 period, following the original equations of the FWI system presented in van Wagner and Pickett (1985), and considering both the daily mean and the 12-UTC instantaneous values. We retained only the data corresponding to summer (JJA), thus focusing the analysis in the season of critical fire danger over the target area (Camia et al, 2008). In each case, we computed:

- The seasonal severity rating (SSR), by aggregating seasonally the DSR. This index is applied in many impact studies and fire prevention programs (van Wagner, 1987).

- The 90-th percentile of FWI (FWI90), which is commonly used as an indicator of extreme fire danger situations (e.g., Andrews et al, 2003; Dowdy et al, 2010).

- The frequency-over-threshold 30 (FOT30), i.e. the number of days with FWI > 30 , expressed as a percentage of the total number of days. Moriondo et al (2006) show informative thresholds on the Mediterranean area that have been also tested (15 and 45). A value of 30 is generally considered as an indicator of extreme fire danger situations (Palheiro et al, 2006), even if it can vary from region to region, and therefore it was used as reference in this study.

For spatial comparability both ERA-Interim and RCM datasets were interpolated to a common regular grid of $25 \mathrm{~km}$ resolution, using the nearest-neighbor algorithm only on those original grid points within the land-mask. In doing so, we avoided artifacts due to the transition between sea and land climatic conditions in coastal areas. Finally, in order to assess the skill of daily mean FWI to detect extreme events, defined as values above FWI90, we identified extreme events using the 12-UTC FWI and then we computed the probability of detection (POD) as the percentage of those extreme events detected by the daily mean FWI. 


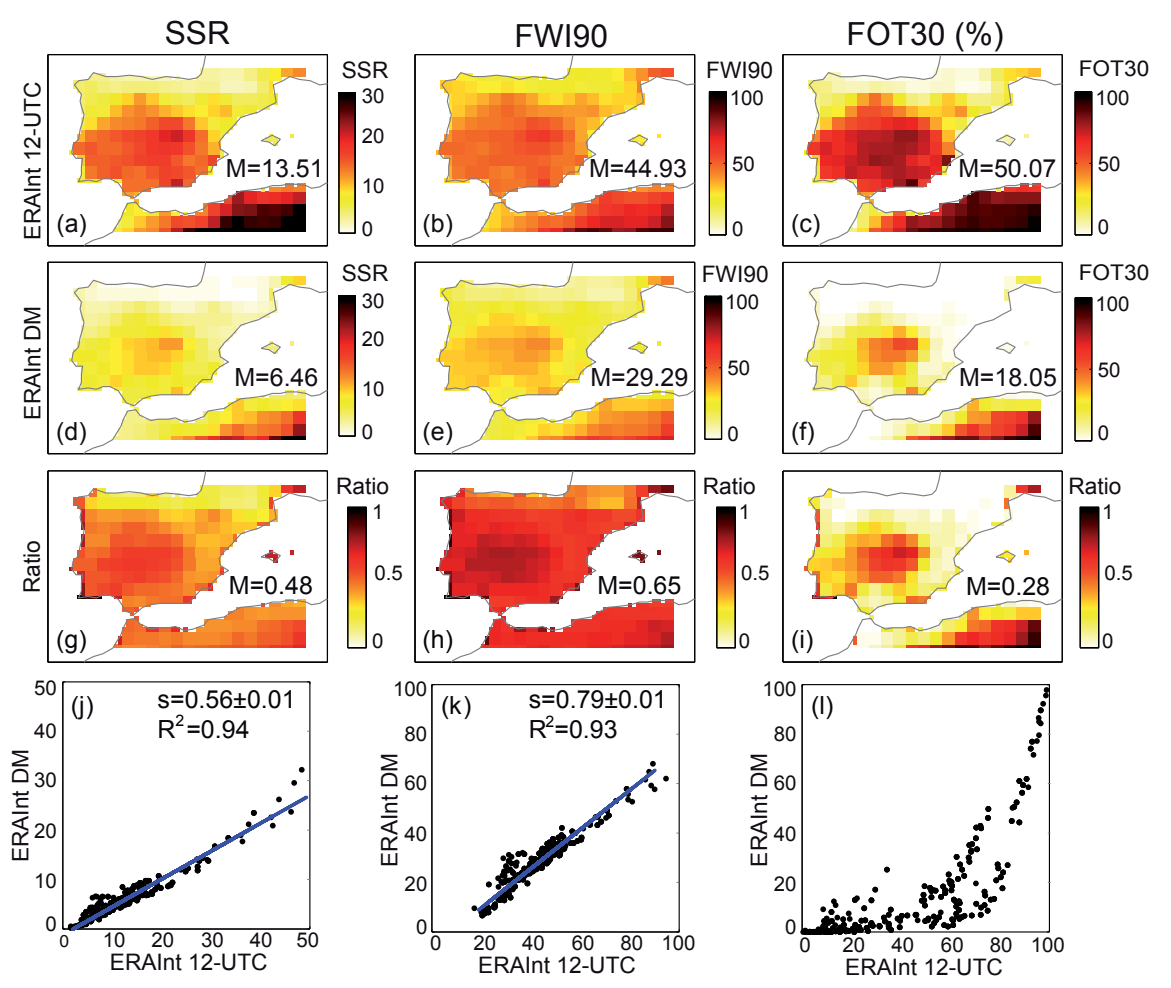

Fig. 1 Seasonal severity rating (SSR), 90th percentile of FWI (FWI90) and frequency-overthreshold 30 (FOT30, in \%), calculated according to ERA-Interim instantaneous data at 12:00 UTC (panels a-c) and ERA-Interim daily mean data (panels d-f). The 'M' values inside the panels show the spatial mean of all grid point values. The differences between 12-UTC and daily mean indices are spatially represented as the ratio of daily mean over 12-UTC values (panels g-i) and as a scatter plot of daily mean vs. 12-UTC values (panels j-l). The slope 's' of the regression lines and the corresponding goodness-of-fit $\mathrm{R}^{2}$ values for SSR and FWI90 are also displayed in panels j-k. Note that for SSR (panels a and d) an upper bound of 30 has been set for a better visualization of the spatial pattern.

\subsection{Future RCM scenario}

We also analyzed the effect of the 12-UTC and daily mean input data on the future projections of fire danger. To this aim, we considered again SSR, FWI90 and FOT30 and analyzed the results of the A1B transient projections obtained with the RCM. In particular, we chose a 20-year future time-slice (2031-2050) and compared the results with those corresponding to the control 20C3M scenario (1981-2000). The climate change signal was obtained by applying the delta method (see, e.g., Räisänen, 2007; Zahn and von Storch, 2010). This method uses the RCM nested in the GCM during a control $(20 \mathrm{C} 3 \mathrm{M})$ period as reference for the future periods. In this way, only differences ("deltas") between future projected variables and control values are considered (thus avoiding absolute values of the variables and partially alleviating the effects of biases). 
4 Results and Discussion

\subsection{Reanalysis Data}

In spite of the marked differences in SSR and FWI90 between 12-UTC and daily mean values, their spatial pattern was similar in both versions, showing a rather constant ratio (Fig. 1). Therefore, the relative fire danger at different locations is at least preserved by the daily mean SSR and FWI90 when compared to their 12-UTC counterparts. In fact, we found a fairly good linear matching between both versions (Fig. 1j-k), with $\mathrm{R}^{2}$ values over 0.9 (i.e. correlation values $\mathrm{R}$ over 0.95 ), in accordance with the findings of other authors using observations data (Carvalho et al, 2010). This suggests the possibility of correcting daily mean FWI to approximate instantaneous FWI by means of a simple empirical linear function. However, a more serious inconsistency was found between different FOT30 versions. For this index, there is not an obvious transformation to correct daily mean FOT30 (Fig. 1-1). Thus, the use of threshold-dependent FWI-derived indices should be avoided when computing daily mean FWI.

\subsection{Regional Climate Models (RCMs)}

Not surprisingly, the results using the reanalysis-driven RCM simulation reproduced similar spatial patterns of fire danger than ERA-Interim (Fig. 2). We found a similar relationship between daily mean and 12-UTC FWI, as previously shown using reanalysis data: (i) a lower magnitude of the indices when using daily mean data (Fig. 2g-i) and (ii) a linear relationship for SSR and FWI90 (Fig. 2j-k), while (iii) FOT30 shows a markedly different spatial pattern (Fig. 2-l).

\subsection{Fire Weather Index System Components}

Similar linear relationships between daily mean and 12-UTC versions were obtained for the different FWI components, as reflected by the high cross-correlation values obtained (Table 1). The results obtained with the reanalysis and with the different RCM simulations were almost identical. Thus, for the sake of simplicity, in Table 1 we only display the results from the reanalysis. The ratio, computed as the quotient of the spatial means of daily mean over 12-UTC FWI, gives an indication of the magnitude of the bias. With this regard, our results highlight a remarkable negative bias of some of the daily mean components, in accordance with our findings for SSR and FWI90. All correlation values were high ( $>0.90$ in all cases), although the lowest ones were obtained by the wind-dependent FWI components (FFMC and ISI), pointing to daily mean wind as the main source of error in the linear fits between 12-UTC and daily mean FWI values. The magnitude of the daily mean component biases differed markedly. In the case of FFMC, the bias was small (ratio=0.94, Table 1 ). On the contrary, the largest bias was found for ISI, in which the magnitude of daily mean version was nearly half that of the 12 -UTC version (ratio=0.55). In order to disentangle the relative contribution of each input variable on the FWI component biases, we ran a simple sensitivity analysis. To this aim, we replaced one by one each of the instantaneous variables by their daily mean counterparts, and calculated for each combination the resulting cross-correlation and ratio. The sensitivity analysis (Table 1) reveals the input 

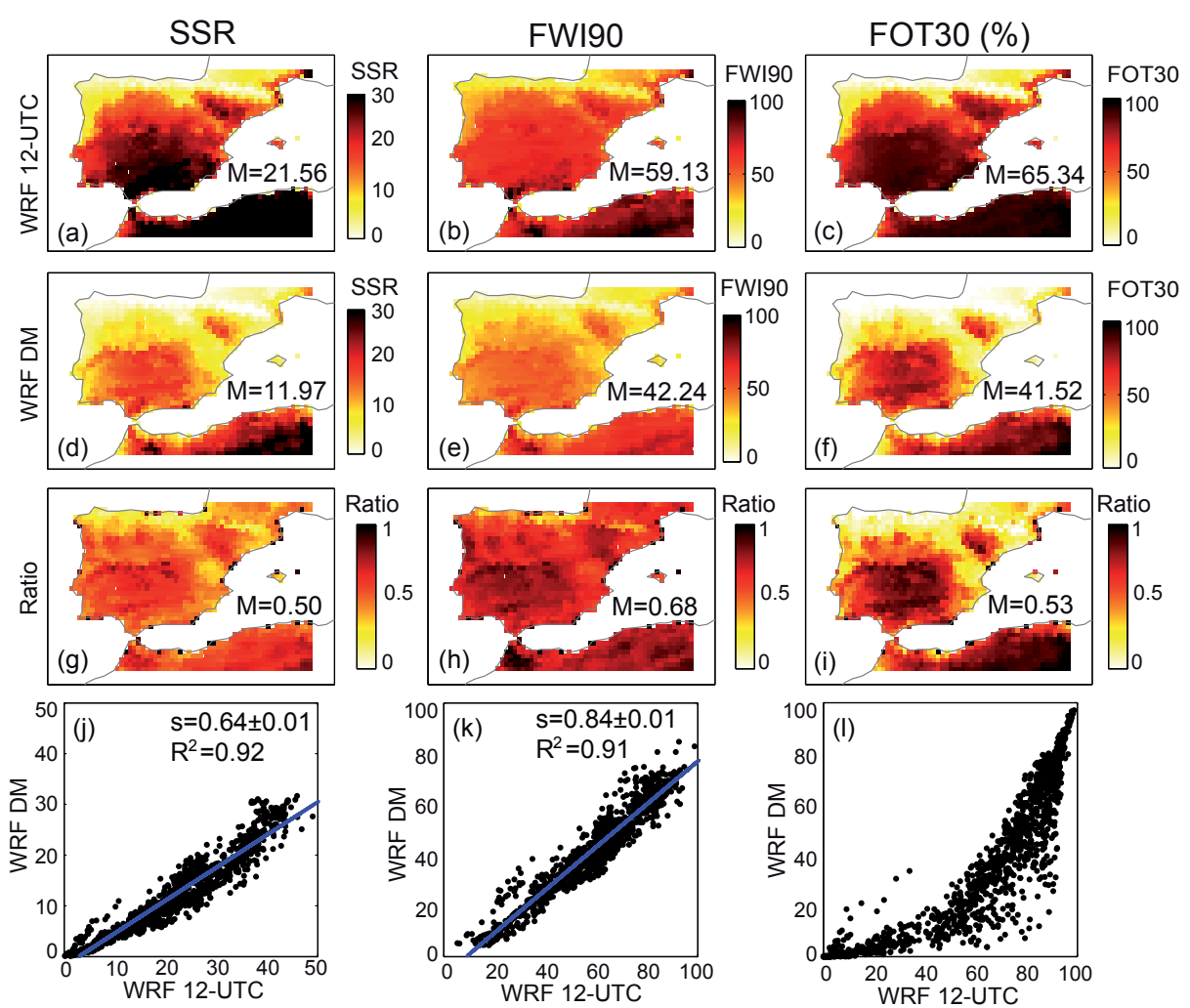

Fig. 2 As Figure 1, but for the RCM simulation corresponding to the 12-UTC (panels a-c) and daily mean model outputs (panels d-f). The ratio of the indices daily mean over 12-UTC (panels g-i) and the corresponding scatter plots are shown in panels j-l. Note that for SSR (panels a and d) an upper bound of 30 has been set for a better visualization of the spatial pattern.

variables involved in the calculation of each component (those that have a correlation with the 12-UTC version lower than 1). In all cases, daily mean relative humidity produced larger negative biases, followed by temperature. Conversely, the replacement of 12-UTC by daily mean wind had the lowest effect on bias.

\subsection{Future Projections of fire risk}

In order to explore the relationships between the deltas derived from 12-UTC and daily mean data, we depicted scatterplots (Fig. 3) corresponding to both the 20C3M and the A1B scenarios of the RCM. We found that an accurate linear model can be fitted between daily mean and instantaneous delta projections of SSR and FWI90 in both scenarios $\left(\mathrm{R}^{2}>0.90\right.$ in both scenarios), although in the case of FOT30 there is no linear model adequately relating both deltas $\left(\mathrm{R}^{2}<0.5\right)$. The promising results achieved in the analysis of 20C3M and A1B projections of SSR and FWI90 separately are nevertheless dissapointing when the corresponding deltas are computed, given that 

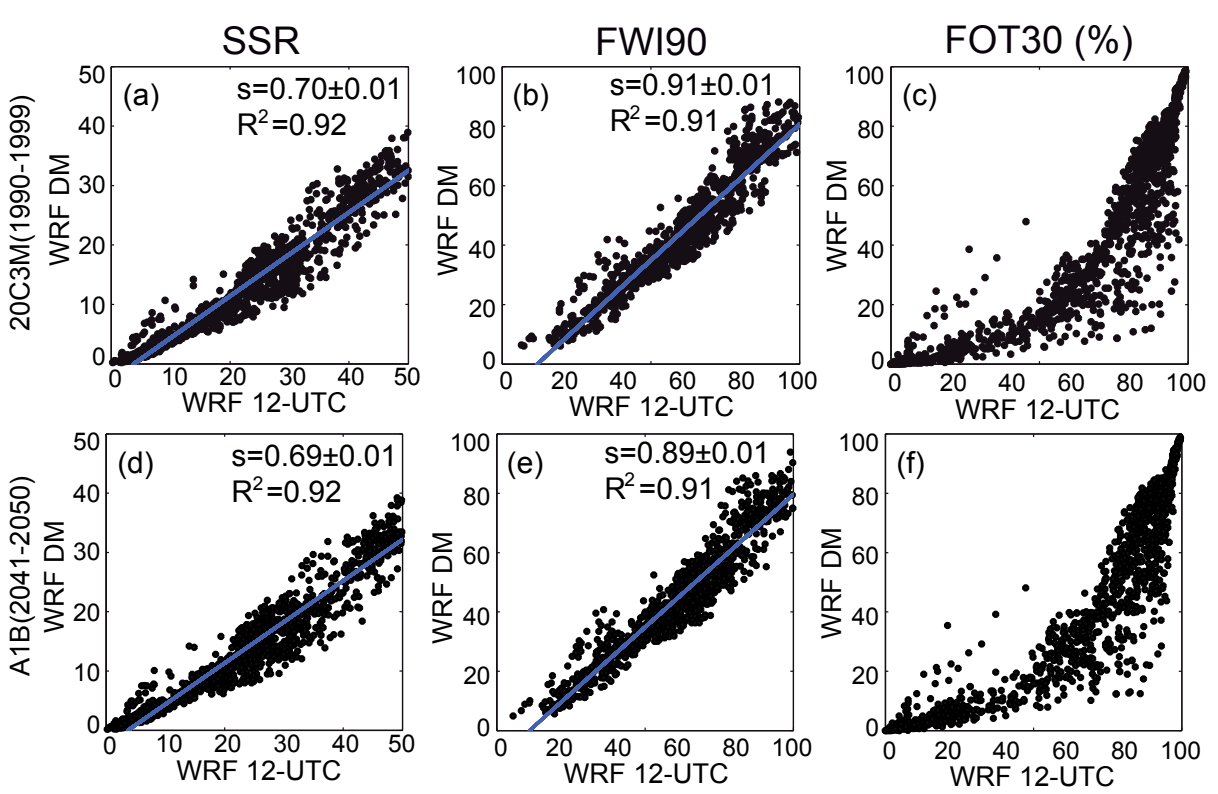

Fig. 3 Linear fits of the daily mean vs. instantaneous fire danger indicators according to the projections of the RCM coupled to the GCM in 20C3M (1990-1999) and A1B (2041-2050) scenarios.

the climate change signal is altered both in magnitude and spatial pattern when daily mean data are used instead of noon data, as depicted in Fig. 4. According to our results the different slopes found for the linear fits of the 20C3M and A1B scenarios (Fig. 3) lead to worse linear fits of the resulting deltas (Fig. 4g-i).

For SSR, the delta signals (Fig. 4a and d) show that 12-UTC and daily mean-based indices exhibit similar spatial patterns (notice the high spatial correlation, $\mathrm{R}=0.93$ ), although the magnitude of the climate change signal is higher for the 12-UTC version. Conversely, the climate change signal for FOT30 (Fig. 4c and f) shows different spatial distributions depending on the use of 12-UTC or daily mean data. Using 12-UTC data, a FOT30 decrease is projected over many areas of the Iberian Peninsula (blue colors), mainly over the western part. The spatial extent of this FOT30-decrease shrinks significantly when using daily mean data, becoming restricted to southwestern Iberia (Fig. 4f). A pattern mainly dominated by a FOT30 increase is shown and the spatial correlation is much lower than for $\operatorname{SSR}(\mathrm{R}=0.6)$. The same result was found after testing other reference thresholds (FOT15 and FOT45). These results indicate that by computing FWI with daily mean data instead of instantaneous values, contradictory FOT30 projections can be obtained, even if the same RCM is used. This highlights the significant effect of 12-UTC vs. daily mean input data on the future projections of FOT30. FWI90 (Fig. 4b and e) shows an intermediate behavior (the spatial correlation is $\mathrm{R}=0.76$ ), with slight to moderate inconsistencies in its spatial pattern, depending on the sub-regions. 


\begin{tabular}{llcccc}
\hline \multirow{2}{*}{ FFMC } & & All DM & RelH DM & Temp DM & Wind DM \\
& ratio & 0.937 & $\mathbf{0 . 9 5 6}$ & 0.984 & 0.998 \\
& rho & 0.983 & 0.992 & 0.998 & 0.999 \\
\hline \multirow{2}{*}{ DMC } & ratio & 0.634 & $\mathbf{0 . 7 4 8}$ & 0.852 & 1.000 \\
& rho & 0.984 & 0.990 & 1.000 & 1.000 \\
\hline \multirow{2}{*}{ DC } & ratio & 0.859 & 1.000 & 0.859 & 1.000 \\
& rho & 0.997 & 1.000 & 0.997 & 1.000 \\
\hline \multirow{2}{*}{ ISI } & ratio & 0.547 & $\mathbf{0 . 6 7 3}$ & 0.873 & 0.927 \\
& rho & 0.966 & 0.986 & 0.999 & 0.994 \\
\multirow{2}{*}{ BUI } & ratio & 0.690 & $\mathbf{0 . 8 1 0}$ & 0.855 & 1.000 \\
& rho & 0.992 & 0.995 & 0.999 & 1.000 \\
\hline \multirow{2}{*}{ FWI } & ratio & 0.601 & $\mathbf{0 . 7 1 7}$ & 0.884 & 0.955 \\
& rho & 0.977 & 0.990 & 0.998 & 0.997 \\
\hline
\end{tabular}

Table 1 Results of the comparison of different daily mean versions of the FWI components vs. the 12-UTC instantaneous ones (see Section 3 for details and acronym definition). Data presented correspond to the ERA-Interim reanalysis (results are similar for RCM simulations, not shown). Statistics presented correspond to the spatial means of the results, namely: the ratio daily mean/12-UTC and the Spearman's correlation coefficient (rho). In the first column ("all DM"), the results of the daily mean versus 12 -UTC version are compared. In the following columns, the comparison is done against a modified 12-UTC version in which only one of the instantaneous variables is replaced by its daily mean version. Larger biases (as revealed by lower ratios) are highlighted in boldface.

\subsection{Detection of Extreme Events}

In order to test the ability of daily mean data to detect fire danger extremes, we considered the ERA-Interim 12-UTC data as the reference series for extreme event detection and computed the POD attained by the ERA-Interim daily mean version (Fig 5a). To this aim, we used data for the 1990-99 period. There is an average detection POD of $55 \%$, and thus $45 \%$ of the extreme events occurring in the instantaneous FWI climatology are missed by the corresponding daily mean counterpart. Similarly, Fig. 5b shows the probability of detection of daily mean output data of an extreme event defined by a RCM reanalysis-driven simulation (1990-99) using the 12-UTC data. As it can be seen, in the case of the RCM simulation, the average POD is only marginally higher than for ERA-Interim.

\section{Conclusions}

The FWI indices based on instantaneous data at noon, as originally defined by van Wagner (1987), provided higher values of SSR, FWI90 and FOT30 than their daily mean counterparts, whose magnitudes were in all cases negatively biased. According to reanalysis and RCM data, a simple linear model might be used to approximate 12UTC fire danger present climatologies from daily mean data, in the case of SSR and FWI90. This is not the case for FOT30, for which a more complex relationship was unveiled.

In the case of future regional fire danger projections, differences found between daily mean and 12-UTC data were critical, to the extent that climate change signals were not consistent in some cases. Future increases projected for daily mean-based SSR preserve the spatial pattern of the 12-UTC version. However different delta values (even of opposite signs) were obtained for FWI90 and, specially, FOT30 when using 

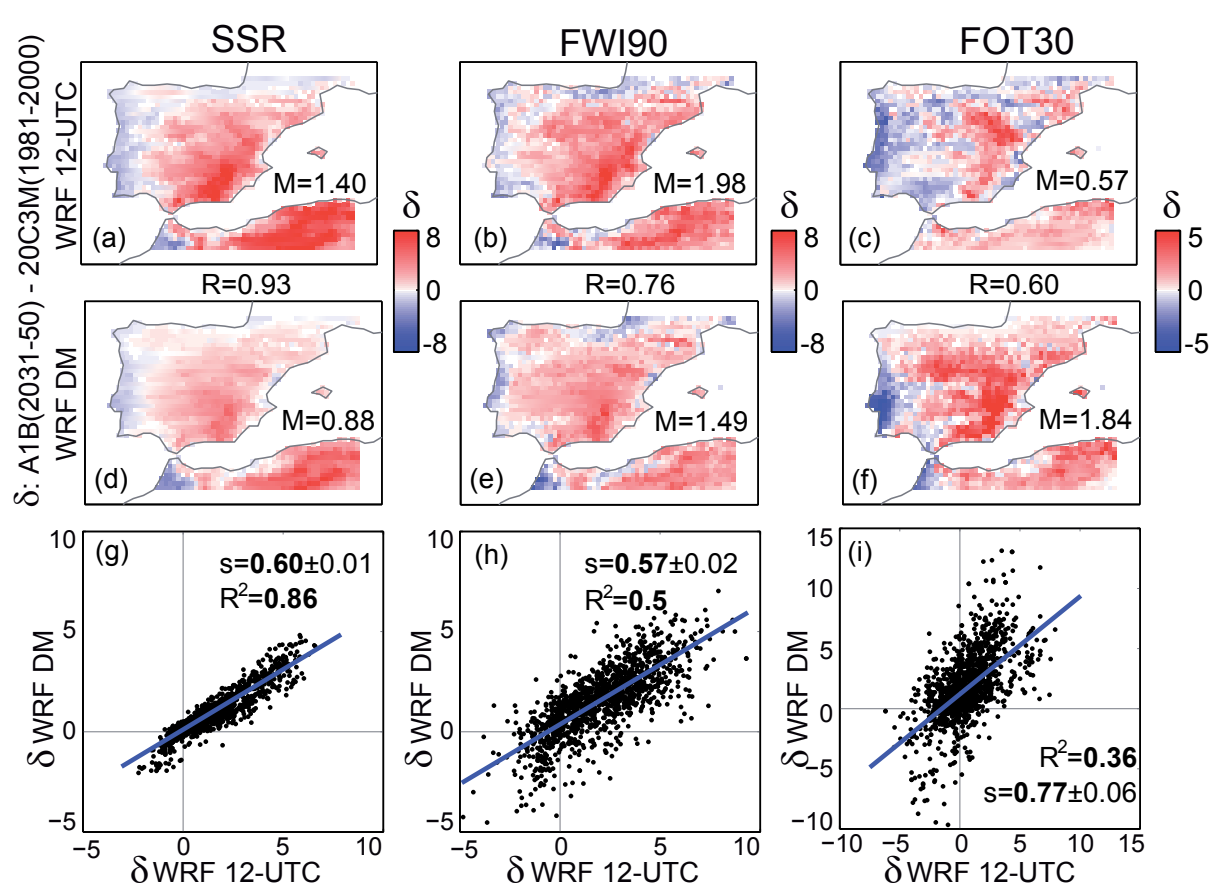

Fig. 4 Climate change signal of SSR, FWI90 and FOT30 obtained from the RCM transient (A1B) and control (20C3M) simulations applying the "delta" method (see section 3.2). The first row shows 12-UTC indices as deltas for the period 2031-2050. The second row shows the deltas for the same indices computed from daily mean data. The spatial correlation $R$ among each pair of fields is given in the figure. The last row compares the spatial patterns of the deltas as a scatter plot of daily mean vs 12 -UTC values. Moreover, the slope and goodness-of-fit $\mathrm{R}^{2}$ of the linear model fitted to the scatter plots are also shown.

instantaneous or daily mean data. As a result, future delta patterns of daily meanbased SSR might be corrected using a linear transformation, but there is no obvious reliable cure for FWI90 and FOT30 in order to approximate their 12-UTC values. In the context of climate change studies in Europe, this could be particularly problematic, since some of the most popular regional climate databases provide only daily mean values for the variables required for FWI calculation. This is the case, for instance, of the ENSEMBLES RCM database, which is to date the best available source of high resolution projections for Europe (http://ensemblesst3.dmi.dk).

Moreover, using reanalysis and RCM data our results indicate that the use of daily mean FWI produces a slight to moderate loss of extreme event detection skill with respect to the 12-UTC original version, an issue of critical importance in the framework of fire research.

In conclusion, our results warn against the use of daily mean data for the computation of the FWI set of indices, in spite of the possible adjustment that could be carried out in some particular cases. Further research on this subject might be needed in order to ascertain if the linear correction coefficients are similar between different $\mathrm{RCMs}$ and/or geographical domains or, on the contrary, corrections require a more specific analysis for each particular case, although in any case the most reasonable 
(a) ERAInt 12-UTC vs DM

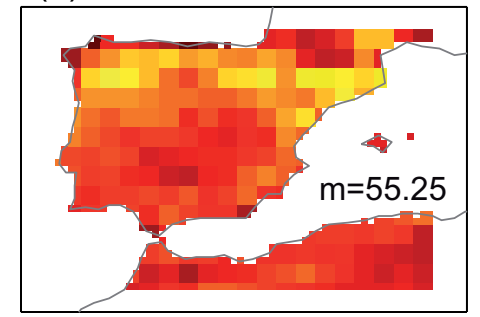

(b) WRF 12-UTC vs DM

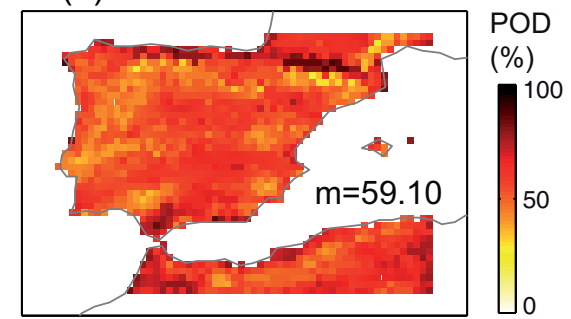

Fig. 5 Probability of detection (\% of days, POD) of extreme fire danger events (as given by 12-UTC data) using daily mean data, according to (a) ERA-Interim and (b) RCM simulations nested into ERA-Interim. Spatial means indicated by the $m$ values.

solution seems the use of adequate input data prior to FWI calculation, given the misleading results obtained with the daily mean data sources used in this study. Although mean fire danger patterns are preserved in future daily mean projections, no consistent conclusions can be extracted about future fire danger regime, including the frequency and magnitude of extreme events, unless the appropriate instantaneous input data are used. Furthermore, no possible adjustment of daily mean estimates can be accomplished unless the appropriate 12-UTC data are available.

Acknowledgements The research leading to these results has received funding from the European Union's Seventh Framework Programme (FP7/2007-2013) under grant agreement 243888 (FUME Project). J.F. acknowledges financial support from the Spanish R\&D\&I programme through grant CGL2010-22158-C02 (CORWES project).

The ESCENA project (200800050084265) of the Spanish "Strategic action on energy and climate change" provided the WRF RCM simulation used in this study. We acknowledge three anonymous referees for their useful comments that helped to improve the original manuscript.

\section{References}

Andrews P, Loftsgaarden D, Bradshaw L (2003) Evaluation of fire danger rating indexes using logistic regression and percentile analysis. Int J Wildland Fire 12:213-226

Bedia J, Herrera S, Gutiérrez J, Zavala G, Urbieta I, Moreno J (2012) Sensitivity of Fire Weather Index to different reanalysis products in the Iberian Peninsula. Nat Hazards Earth Syst Sci 12:699-708, DOI 10.5194/nhess-12-699-2012

Brands S, Herrera S, San-Martín D, Gutiérrez J (2011) Validation of the ENSEMBLES global climate models over southwestern Europe using probability density functions, from a downscaling perspective. Clim Res 48:145-161

Brands S, Gutiérrez J, Herrera S, Cofiño A (2012) On the use of reanalysis data for downscaling. J Clim 25:2517-2526, DOI 10.1175/JCLI-D-11-00251.1

Brown T, Hall B, Westerling A (2004) The impact of twenty-first century climate change on wildland fire danger in the westerns United States: An applications perspective. Clim Change 62:365-388

Camia A, Amatulli G, San Miguel-Ayanz J (2008) Past and future trends of forest fire danger in Europe. Tech. Rep. EUR 23427 EN - 2008, Institute for Environment and Sustainability, Joint Research Centre, European Comission, Ispra, Italy 
Carvalho A, Flannigan MD, Logan K, Miranda AI, Borrego C (2008) Fire activity in Portugal and its relationship to weather and the Canadian Fire Weather Index System. Int J Wildland Fire 17:328-338

Carvalho A, Flannigan MD, Logan KA, Gowman L, Miranda AI, Borrego C (2010) The impact of spatial resolution on area burned and fire occurrence projections in Portugal under climate change. Clim Change 98:177-197

Chandler C, Cheney P, Thomas P, Trabaud L, Williams D (1983) Fire in forestry. Forest fire behavior and effects, vol 1. Wiley, New York, USA

Christensen J, Carter T, Rummukainen M, Amanatidis G (2007) Evaluating the performance and utility of regional climate models: the PRUDENCE project. Clim Change 81:1-6, DOI 10.1007/s10584-006-9211-6

Costa L, Thonicke K, Poulter B, Badeck F (2011) Sensitivity of Portuguese forest fires to climatic, human, and landscape variables: subnational differences between fire drivers in extreme fire years and decadal averages. Regional Environ Change 11:543-551

de Groot W, Goldammer J, Keenan T, Brady M, Lynham T, Justice C, Csiszar I, O'Loughlin K (2006) Developing a global early warning system for wildland fire. Forest Ecol Manag 234:S10, DOI 10.1016/j.foreco.2006.08.025

Dee DP, Uppala SM, Simmons AJ, Berrisford P, Poli P, Kobayashi S, Andrae U, Balmaseda MA, Balsamo G, Bauer P, Bechtold P, Beljaars ACM, van de Berg L, Bidlot J, Bormann N, Delsol C, Dragani R, Fuentes M, Geer AJ, Haimberger L, Healy SB, Hersbach H, Hólm EV, Isaksen L, Kållberg P, Köhler M, Matricardi M, McNally AP, Monge-Sanz BM, Morcrette J, Park B, Peubey C, de Rosnay P, Tavolato C, Thépaut JN, Vitart F (2011) The ERA-Interim reanalysis: configuration and performance of the data assimilation system. Quart J R Meteorol Soc 137:553597

Domínguez M, Romera R, Sánchez E, Fita L, Fernández J, Jiménez-Guerrero P, Montávez JP, Cabos WD, Liguori G, Gaertner MA (2012) Present climate precipitation and temperature extremes over Spain from a set of high resolution RCMs. Clim Res Submitted

Dosio A, Paruolo P (2011) Bias correction of the ENSEMBLES high-resolution climate change projections for use by impact models: Evaluation on the present climate. $\mathrm{J}$ Geophys Res 116, DOI 10.1029/2011JD015934

Dowdy A, Mills G, Finkele K, deGroot W (2010) Index sensitivity analysis applied to the Canadian Forest Fire Weather Index and the McArthur Forest Fire Danger Index. Meteorol Appl 17:298-312

Feser F, Rockel B, von Storch H, Winterfeldt J, Zahn M (2011) Regional climate models add value to global model data. Bull Amer Meteor Soc 92(9):1181-1192

Flannigan M, Harrington J (1988) A study of the relation of meteorological variables to monthly provincial area burned by wildfire in Canada 1953-80. J Appl Meteorol 27:441-452

Flannigan M, Logan K, Amiro B, Skinner W, Stocks B (2005) Future area burned in canada. Climatic Change 72(1-2):1-16, DOI doi:10.1007/s10584-005-5935-y

Fugioka FM, Gill A, Viegas DX, Wotton B (2009) Fire Danger and Fire Behavior Modeling Systems in Australia, Europe, and North America. In: Bytnerowicz A, Arbaugh M, Riebau A, Andersen C (eds) Developments in Environmental Science, Elsevier B.V., The Netherlands

Giannakopoulos C, Le Sager P, Bindi M, Moriondo M, Kostopoulou E, Goodess C (2009) Climatic changes and associated impacts in the Mediterranean 
resulting from a 2 degrees $\mathrm{C}$ global warming. Glob Planet Change DOI 10.1016/j.gloplacha.2009.06.001

Good P, M M, C G, M B (2008) The meteorological conditions associated with extreme fire risk in italy and greece: relevance to climate model studies. Int J Wildland Fire $17: 155-165$

Hennessy K, Lucas C, Nicholls N, Bathols J, Suppiah R, Ricketts J (2005) Climate change impacts on fire-weather in south-east Australia. Tech. rep., CSIRO Marine and Atmospheric Research and Bushfire CRC and Australian Bureau of Meteorology, Australia

Jiménez PA, Dudhia J (2012) Improving the Representation of Resolved and Unresolved Topographic Effects on Surface Wind in the WRF Model. J Appl Meteor Climatol 51:300-316

Jiménez-Guerrero P, Montávez JP, Domínguez M, Romera R, Fita L, Fernández J, Cabos WD, Liguori G, Gaertner MA (2012) Description of mean fields and interannual variability in an ensemble of RCM evaluation simulations over Spain: results from the ESCENA project. Clim Res Submitted

Krawchuk M, Moritz M A, Parisien M A, van Dorn J, Hayhoe K (2009) Global Pyrogeography: the Current and Future Distribution of Wildfire. PLoS ONE 4:e5102, DOI 10.1371/journal.pone.0005102

Littell J, McKenzie D, Peterson D, Westerling A (2009) Climate and wildfire area burned in western U.S. ecoprovinces, 1916-2003. Ecological Applications 19:10031021

Moreno J, Zavala G, Martin M, Millán A (2010) Forest fire risk in spain under future climate change. In: Settele J, Penev L, Georgiev T, Grabaum R, Grobelnik V, Hammen V, Klotx S, Kotarac M, Kuehn I (eds) Atlas of Biodiversity Risks, Pensoft, Sofia \& Moscow, pp 72-73

Moriondo M, Good P, Durao R, Bindi M, Giannakopoulos C, Corte-Real J (2006) Potential impact of climate change on fire risk in the mediterranean area. Clim Res 31:85-95

Nakićenović N (2000) Greenhouse Gas Emissions Scenarios. Technological Forecasting and Social Change 65:149-166, DOI 10.1016/S0040-1625(00)00094-9

Palheiro P, Fernandes P, Cruz M (2006) A fire behaviour-based fire danger classification for maritime pine stands: Comparison of two approaches. Forest Ecol Manag pp 234S, S54

Pechony O, Shindell DT (2010) Driving forces of global wildfires over the past millennium and the forthcoming century. P Natl Acad Sci USA 107(45):19,167-19,170, DOI 10.1073/pnas.1003669107

Räisänen J (2007) How reliable are climate models? Tellus A 59:2-29

Roeckner E (2007) ENSEMBLES ECHAM5-MPI-OM 20C3M run2, monthly mean values. World Data Center for Climate. CERA-DB "ENSEMBLES_MPEH5_20C3M_2_MM" Available at http://cera-www.dkrz.de /WDCC/ui/Compact.jsp?acronym= ENSEMBLES_MPEH5_20C3M_2_MM

Rothermel R (1972) A mathematical model for predicting fire spread in wildland fuels. Research Paper INT-115, USDA Forest Service, Intermountain Forest and Range Experiment Station, 40 pp.

Seneviratne S, Nicholls N, Easterling D, Goodess C, Kanae S, Kossin J, Luo Y, Marengo J, McInnes K, Rahimi M, Reichstein M, Sorteberg A, Vera C, Zhang X (2012) Changes in climate extremes and their impacts on the natural physical environment. In: Field C, Barros V, Stocker T, Qin D, Dokken D, Ebi K, Mastrandrea M, Mach 
K, Plattner GK, Allen S, Tignor M, Midgley P (eds) Managing the Risks of Extreme Events and Disasters to Advance Climate Change Adaptation, Cambridge University Press, Cambridge, UK, and New York, USA, pp 109-230

Skamarock W, Klemp J, Dudhia J, Gill D, Barker D, Duda M, Huang XY, Wang W, Powers J (2008) A Description of the Advanced Research WRF Version 3. NCAR Technical Note 475, NCAR, Boulder, CO, USA

Sterl A (2004) On the (in)homogeneity of reanalysis products. J Clim 17(19):3866-3873

Stocks B, Fosberg M, Lynham T, Mearns L, Wotton B, Yang Q, Jin JZ, Lawrence K, Hartley G, Mason J, McKenney D (1998) Climate change and forest fire potential in Russian and Canadian boreal forests. Clim Change 38:1-13

Strauss D, Bednar L, Mees R (1989) Do One Percent of the Forest Fires Cause NinetyNine Percent of the Damage? Forest Sci 35:319-328

Themeßl M, Gobiet A, Heinrich G (2011) Empirical-statistical downscaling and error correction of regional climate models and its impact on the climate change signal. Clim Change DOI 10.1007/s10584-011-0224-4

van der Linden P, Mitchell J (2009) ENSEMBLES: Climate change and its impacts: Summary of research and results from the ENSEMBLES project. Tech. rep., Met Office Hadley Centre, Exeter, UK

Vázquez A, Moreno J (1993) Sensitivity of fire occurrence to meteorological variables in Mediterranean and Atlantic areas of Spain. Landscape and Urban Planning 24:129142

Vázquez A, Moreno J (1995) Patterns of fire occurrence across a climatic gradient and its relationship to meteorological variables in Spain. In: Moreno J, Oechel W (eds) Global Change and Mediterranean-Type Ecosystems, Ecological Studies, vol 117, Springer Verlag, New York, USA

van Wagner CE (1987) Development and structure of the Canadian Forest Fire Weather Index. Forestry Tech. Rep. 35, Canadian Forestry Service, Ottawa, Canada

van Wagner CE, Pickett TL (1985) Equations and FORTRAN program for the Canadian forest fire weather index system. Forestry Tech. Rep. 33, Canadian Forestry Service, Ottawa, Canada

Wotton B, Alexander M, Taylor S (2009) Updates and revisions to the 1992 canadian forest fire behavior prediction system. Information Report GLC-X-10, Natural Resources Canada, Canadian Forest Service, Great Lakes Forestry Centre, Sault Ste. Marie, Ontario, Canada

Wotton BM (2009) Interpreting and using outputs from the Canadian Forest Fire Danger Rating System in research applications. Environ Ecol Stat 16:107-131, DOI 10.1007/s10651-007-0084-2

Zahn M, von Storch H (2010) Decreased frequency of North Atlantic polar lows associated with future climate warming. Nature 467:309-312 